"Nuevo Sindicalismo" y Represión Judicial en el Brasil de la "apertura": las huelgas metalúrgicas en São Bernardo do Campo y São José dos Campos (1980-85)

Richard De Oliveira Martins

páginas / año 12 - n 28 Enero-Abtil / ISSN 1851-992X/ 2020

http://revistapaginas.unr.edu.ar/index.php/RevPaginas

\title{
"Nuevo Sindicalismo" y Represión Judicial en el Brasil de la "apertura": las huelgas metalúrgicas en São Bernardo do Campo y São José dos Campos (1980-85)
}

\author{
"New Unionism" and Judicial Represion in the Brazilian "political \\ openinig": metalworkers' strikes in São Bernardo do Campo and \\ São José dos Campos (1980-85)
}

\author{
Richard De Oliveira Martins \\ Instituto de Filosofia e Ciências Humanas; \\ Universidade Estadual de Campinas; \\ Fundação de Amparo à Pesquisa do Estado de São Paulo (Brasil) \\ o.m.richard@gmail.com
}

\begin{abstract}
Resumen
En el presente texto, tratamos de algunas de las diferentes modalidades de represión judicial con que se depararon liderazgos y activistas metalúrgicos como consecuencia de su participación en los movimientos huelguistas que marcaron el período de la llamada "apertura política" brasileña. Partimos del fracaso del intento de criminalización de algunos de los dirigentes metalúrgicos de São Bernardo do Campo/SP, tras la huelga que condujeron en 1980, enjuiciados en la Ley de Seguridad Nacional. Años después, ya bajo Sarney, cuando activistas y sindicalistas metalúrgicos de São José dos Campos/SP también fueron procesados criminalmente como resultado de su participación en una huelga con ocupación de fábrica, la nueva LSN aprobada en 1983 no fue movilizada; la represión promovida por el Gobierno provincial de San Pablo contra los huelguistas se amparó en artículos del Código Penal, en un evidente intento de caracterizarlos como simples criminales. Sostenemos que esta táctica de represión judicial tenía la intención de deslegitimar la huelga, ocultando el carácter también político de la represión.
\end{abstract}

\section{Palabras clave}

Represión; Nuevo Sindicalismo; Leyes de Seguridad Nacional; Huelgas; Movimiento Obrero.

\begin{abstract}
In this paper, we deal with some of the different modalities of judicial repression with which metalworkers' leaders and activists came across as a consequence of their participation in the strikes that marked the period of the Brazilian political distension. We start from the failure of the attempts to criminalize some of the trade unionists of São Bernardo do Campo / SP, during the strike they led in 1980, when these leaders were prosecuted by the National Security Act (LSN). A few years later, under Sarney's government, when activists and trade uniniosts from the metallurgical industry of São José dos Campos were also criminally prosecuted, as a result of their participation in a strike that led to the occupation of a factory, the case was based in articles from Brazil's Penal Code, instead of dictatorship's exception

Esta obra está sujeta a la Licencia Reconocimiento-NoComercial-CompartirIgual 4.0 Internacional de Creative Commons. http://creativecommons.org/licenses/by-nc-sa/4.0/

(cc) EY-NC-SA
\end{abstract}




\section{Richard De Oliveira Martins}

laws, still in force. We maintain that this tactic of judicial repression was intended to delegitimize the strike, hiding the political nature of the repression.

\section{Keywords}

Repression; New Unionism; National Security Acts; Strikes; Worker's Movement.

\section{Introdución}

En los últimos años, historiadores han señalado que, en el marco de los estudios sobre la dictadura civil-militar brasileña (1964-1985), las temáticas del mundo del trabajo y de las experiencias de los trabajadores - especialmente en lo referente al período anterior a 1978, año en que se inician las famosas "huelgas del ABC" estuvieron, durante mucho tiempo, relegados a un lugar secundario, o incluso ausentes. Si tomamos en cuenta la primacía de la emergencia de estudios sobre otros fenómenos y segmentos sociales afectados por la dictadura (lucha armada, movimiento estudiantil, intelectuales y artistas), aliada a - y, quizás, derivada de una interpretación dominante según la cual los trabajadores no habrían resistido el golpe, siendo indirectamente "responsables" por la dictadura, es más fácil comprender el interés tardío de la historiografía sobre la experiencia obrera bajo el régimen inaugurado en 1964. Como sostienen Corrêa y Fontes, incluso el ascenso huelguista a partir de 1978 parece no haber estimulado una alteración inmediata de la agenda de estudios en el campo de la historia social: si muchos cientistas sociales se dedicaron a comprender los fenómenos del llamado "nuevo sindicalismo" y los "nuevos movimientos sociales" - categorías más tarde revisadas y problematizadas - que les eran contemporáneos, "las huelgas de la redemocratización parecen haber inspirado a los historiadores a analizar otro período de supuesta autonomía y prevalencia de las prácticas clasistas - el inicio del siglo XX, en particular la actuación de los anarquistas y sindicalistas revolucionarios" (Corrêa \& Fontes, 2016: 138). También de acuerdo con los autores:

\footnotetext{
“el carácter represivo y controlador del régimen, que prácticamente intentaba hacer de los sindicatos brasileños una extensión del Estado, pudo haber dado la impresión de que no había nada interesante que estudiar en aquel período, salvo las escasas manifestaciones de resistencia por parte de la clase obrera. De esta manera, la idea de que el sindicalismo brasileño se durmió en 1964, tuvo un espasmo en 1968 y despertó agitado diez años después - cuando el llamado 'nuevo sindicalismo' emergió - todavía permanece, aunque algunos trabajos publicados en la última década han comenzado a deconstruir esta idea" (Corrêa \& Fontes, 2016: 139) ${ }^{1}$
}

\footnotetext{
${ }^{1}$ Las traducciones de las citas de trabajos publicados originalmente en idioma portugués o inglés son de mi responsabilidad.
} 


\section{"Nuevo Sindicalismo" y Represión Judicial en el Brasil de la "apertura": las huelgas metalúrgicas en São Bernardo do Campo y São José dos Campos (1980-85)}

Si los primeros estudios sobre el "nuevo sindicalismo", casi siempre amparados en la experiencia de los metalúrgicos de la región de São Bernardo do Campo, enfatizaban exactamente su supuesta novedad (caracterizada esencialmente por una mayor participación de las bases en los procesos decisorios y de movilización, y por el rechazo a la estructura sindical oficial), otros trabajos demostraron que estas prácticas tenían antecedentes claros en la historia del movimiento obrero brasileño (Morel \& Mangabeira, 1994; Mattos, 1998; Negro, 1999; 2004) y que el ascenso de finales de la década de 1970 podía ser mejor comprendido como el "resultado de una lucha silenciosa y de una resistencia cotidiana en el espacio fabril, en los lugares de trabajo y vivienda, a menudo al margen de los sindicatos, en los bordes de la represión" (Corrêa \& Fontes, 2016: 138). Más recientemente, historiadores han buscado ampliar sus investigaciones sobre el tema, en términos geográficos y cronológicos, abarcando otras regiones y categorías de trabajadores (Guerra, 2015; Rezende, 2017). Aunque en gran parte de esta producción, la represión de las iniciativas de organización y lucha obreras aparece como un elemento ineludible de la experiencia de las clases trabajadoras, parece haber pocos estudios dedicados a comprender las formas y la lógica de estos procesos represivos.

Entre los autores que estudiaron los fenómenos del llamado "nuevo sindicalismo" y la reanudación de la actividad huelguista masiva en Brasil a partir de 1978, parece consensuada la interpretación de que la entrada del movimiento obrero en escena influenció significativamente la dinámica de la llamada "apertura política" entonces en curso. Aprovechándose de elementos coyunturales favorables a la expresión de sus demandas por mejores condiciones de trabajo y remuneración, los metalúrgicos de São Bernardo do Campo (SP) desencadenaron un proceso de luchas que influiría en las movilizaciones en otras regiones y en varias categorías de trabajadores, marcando toda la década siguiente. En cada campaña salarial, nuevos contingentes adoptaban el "método del ABC", experimentando tácticas variadas de movilización, estableciendo vínculos entre trabajadores de diversas ramas y localidades, y a menudo atrayendo la solidaridad de amplios sectores de la población. Como consecuencia, se alteraba el nivel organizativo sindical y político de la clase trabajadora brasileña, algo que sólo podría profundizar la crisis terminal del régimen dictatorial impuesto por el golpe de 1964.

Aunque se inaugurase entonces un contexto que se podría presumir más democrático, la represión estatal y patronal a las movilizaciones obreras indicaba que se pretendía imponer límites bastante restringidos a las protestas de trabajadores. Como señaló Keck (1988: 393), si hubo una mayor disposición obrera a la huelga, también hubo "la certeza de represión por parte del gobierno". La judicialización de esos conflictos tuvo lugar en al menos tres ámbitos: la justicia laboral, la justicia militar y la justicia común (en las instancias estaduales y Federal); son las últimas las que más nos interesan aquí, teniendo en vista su asociación directa con el fenómeno de la criminalización de las luchas sociales, que seguramente 


\section{Richard De Oliveira Martins}

puede ser caracterizado como uno de los más concretos impedimentos a la consolidación de una efectiva democracia en la "Nueva República" brasileña.

Sin embargo, con respecto a la Justiça do Trabalho brasileña, cabe mencionar, de paso, que especialmente en las dos últimas décadas han surgido una serie de estudios que utilizan documentación procedente de causas laborales para explorar una amplia gama de cuestiones relacionadas con el mundo del trabajo. Algunas de estas investigaciones (Corrêa, 2013; Rezende, 2013) demuestran que incluso durante la dictadura civil-militar, la justicia laboral ha sido considerada y utilizada por trabajadores y sindicatos, con variados grados de éxito, como un campo de batalla en sus luchas por derechos, fenómeno que explica los intentos dictatoriales de limitar la Justicia Laboral, colocándola en una "camisa de fuerza", para utilizar la expresión de Fernando Teixeira da Silva (2013: 253).

En el presente texto, tratamos de la represión judicial dirigida contra trabajadores y dirigentes sindicales, en su gran parte vinculados al Partido dos Trabalhadores (PT), que tomaron parte en huelgas durante la década de 1980, acusados de cometer crímenes políticos contra la seguridad nacional, o incluso de infracciones contra el código penal, algo que interpretamos como parte una estrategia de descaracterización de las prácticas sindicales y políticas de la clase obrera, deslegitimadas por el Estado y comparadas a acciones criminales con el fin de justificar la represión e influir en la opinión pública contra las huelgas. Además de inhibir las iniciativas de solidaridad de otros segmentos de la sociedad civil y de la clase obrera, la criminalización pretendía apartar a los líderes obreros del conjunto de los trabajadores movilizados, desincentivando cualquier postura o acción de protesta.

\section{La huelga de los 40 días}

Para desarrollar esta hipótesis, partiremos de la experiencia de la huelga de los metalúrgicos de São Bernardo do Campo y Diadema, iniciada el 1 de abril de 1980, que quedaría conocida como la "huelga de los 40 días". Ricardo Antunes (1992), en A Rebeldia do Trabalho, considera que esa movilización representó un punto de inflexión en la secuencia hasta entonces exitosa de campañas salariales de los sindicalistas metalúrgicos del ABC a partir de 1978, puesto que, en 1980, por primera vez, según el autor, los obreros habían sido claramente derrotados, encerrando su larga huelga "sin que ninguna de sus reivindicaciones esenciales hubieran sido atendidas". Se destaca el peso de la represión que se abatió sobre el "nuevo sindicalismo" de la región, con el propósito de garantizar su contención, incluidas medidas como la detención de los líderes de la huelga y su encuadramiento en la Ley de Seguridad Nacional (LSN), así como la intervención federal sobre el organismo sindical, el Sindicato dos Metalúrgicos de São Bernardo do Campo e Diadema (SMSBCD), "con repercusiones notables y negativas en el conjunto del movimiento huelguista" (Antunes, 1992: 96). 


\title{
"Nuevo Sindicalismo" y Represión Judicial en el Brasil de la "apertura": las huelgas metalúrgicas en São Bernardo do Campo y São José dos Campos (1980-85)
}

Cabe señalar que la intensidad de la represión dirigida contra los huelguistas en la ocasión fue ampliamente reconocida, incluso por autores que no consideraron que el movimiento hubiera sido derrotado, como es el caso de Eder Sader (1995: 27-8). En un trabajo reciente, Francisco Barbosa de Macedo (2015) definió el ciclo de huelgas metalúrgicas de 1978-1980 como "un evento central en la construcción de la democracia en Brasil", y destacó que, en el proceso de "liberalización política controlada" iniciado por los militares ante la crisis del régimen, la esfera pública se veía (sólo) "ligeramente abierta"; también por eso, el movimiento asumió, particularmente en 1980, el "carácter de una rebelión abierta contra el régimen autoritario". ${ }^{2}$ De acuerdo con el autor, la propia dinámica de las movilizaciones ocurridas desde 1978 en São Bernardo, y especialmente la represión patronal contra los huelguistas en 1979, hizo que en 1980 las huelgas salieran las fábricas, ganando las calles y fortaleciéndose a través de las redes de solidaridad construidas en los barrios obreros. ${ }^{3}$ Tales tácticas se hacían aún más necesarias conforme se articulaban las modalidades patronales y estatales de la represión:

\begin{abstract}
"Una serie de acontecimientos dramáticos ocurridos en abril de 1980 tuvo como efecto llevar aún más las concepciones de disenso político y social de los trabajadores para los espacios personales de sus vidas: la declaración de la ilegalidad de la huelga por el TRT [Tribunal Regional do Trabalho] (14 de abril); el crecimiento de la represión policial por la ciudad (a partir del 15 de abril); la intervención federal en el SMSBCD (17 de abril); el inicio de las prisiones de líderes sindicales y activistas (19 de abril); la prohibición de las asambleas en espacios públicos (20 de abril); y las amenazas de despidos, por parte de las directivas de las fábricas, basadas en el argumento de que los huelguistas se habían ausentado del trabajo por treinta días consecutivos, así oficialmente "abandonando sus empleos" (a partir del 23 de abril). Estos eventos contribuyeron a una creciente politización de los espacios y relaciones en el cotidiano de vida de los trabajadores" (Macedo, 2015: 55-6).
\end{abstract}

Macedo apunta, por lo tanto, al menos siete modalidades de la represión dirigidas contra los metalúrgicos del ABC entre 1979 y 1980: por iniciativa de la patronal, a) los despidos o amenazas de despidos, así como b) la expulsión o el cercenamiento del acceso de huelguistas a las plantas de las fábricas; perpetradas por los diferentes

\footnotetext{
2 Macedo, 2015: 38-40.

3 "Si las huelgas metalúrgicas ocurrieron dentro de las fábricas en 1978, en 1979 ellas asumieron el carácter de huelga general que se extendió por las calles de San Bernardo do Campo y de otras ciudades en la región del ABC. Esto se dio en gran medida como resultado de la estrategia represiva adoptada por los propietarios de las fábricas después de las huelgas de 1978. De hecho, a comienzos de 1979, la Federación de las Industrias del Estado de São Paulo (FIESP) instruyó a sus miembros a 'intentar por todos los métodos poner a los huelguistas en las calles'. Los propietarios usaron tal estrategia para explotar su alianza con las fuerzas de seguridad del Estado para minar las acciones obreras. Una vez expulsados de las fábricas y sujetos a la represión policial, los trabajadores desarrollaron nuevas estrategias de movilización, (re)apropiándose del espacio urbano de San Bernardo y mostrando a sus líderes sindicales la importancia de los lazos de vecindad y amistad en el apoyo al movimiento huelguista" (Macedo, 2015: 47).
} 


\section{Richard De Oliveira Martins}

aparatos estatales, tenemos c) las decisiones judiciales por la ilegalidad de las huelgas, $d$ ) las intervenciones federales sobre entidades sindicales, $e$ ) la prohibición de asambleas, reuniones o manifestaciones públicas de los obreros, alcanzando, al menos potencialmente, el conjunto de la clase, y aún ff el encarcelamiento temporario de liderazgos y activistas y $g$ ) la violencia policial aplicada contra los obreros movilizados. A esa lista, debemos añadir también $h$ ) los procesos criminales movidos contra algunos de esos sindicalistas y huelguistas, mencionados por Antunes, cuyo desarrollo se recuperará en líneas generales a continuación.

Los trece sindicalistas presos el 19 de abril (muchos de los cuales fueron liberados apenas el 20 de mayo, diez días después del fin de la huelga), en su mayoría militantes del recién organizado Partido de los Trabajadores, fueron objeto de proceso en la Justicia Militar, a partir de la denuncia que se presentó en julio de 1980, con base en los artículos 36 (incitación a la subversión; pena de reclusión, de 2 a 12 años) y 42 (propaganda subversiva; pena de reclusión, de 1 a 3 años) de la Ley de Seguridad Nacional. En la primera instancia, la Auditoría Militar de São Paulo, once de ellos recibieron sentencias condenatorias, en el día 25 de febrero de 1981. De acuerdo con el PT, este juicio fue marcado por una serie de irregularidades que involucraban el cercenamiento de la defensa (ausencia de intimación de los abogados de defensa), falta de publicidad y, sobre todo, el hecho de que el juez auditor Nelson Guimarães había declarado públicamente ya estar "con la 'convicción firmada' y que la sentencia 'no dependiera de lo que dijeran la defensa y la acusación"”. "Los abogados y los acusados, amparados por la ley, decidieron no comparecer", y los jueces dictaron, como estaba previsto, la condena. A continuación, la defensa recurrió a la instancia superior, el Supremo Tribunal Militar. ${ }^{4}$

Estaba en vigor entonces la quinta versión brasileña de la Ley de Seguridad Nacional, la de no 6.620, del 17/12/1978, decretada por el Congreso Nacional y sancionada por el Presidente Ernesto Geisel, uno de los ideólogos de la "apertura lenta, gradual y segura"; se trataba de la segunda ley sobre el tema editada después del Golpe civilmilitar de 1964. Antes de la llegada de los golpistas al poder, estaba en vigor la LSN de 1953, considerada demasiado blanda por los militares, que la sustituyen en 1967. Según María Celina D'Araújo, sólo entre la LSN de 1967 y la de 1983, los militares bajaron al menos siete textos legales de importancia regulando el asunto. Para la autora:

\footnotetext{
"Esto evidencia cómo en momentos de autoritarismo, las leyes de seguridad nacional pasan por cambios y ganan detalles que apuntan a cuestiones de momento. Son leyes para tratar de coyunturas específicas y que tanto en los años 1930 como en los años 1960, tuvieron en los militares los principales ideólogos y promotores del cambio" (D'Araújo, 2006).
}

\footnotetext{
${ }^{4}$ Las citas son del Boletim Nacional do PT, no 2, maio de 1981, p. 4.
} 


\section{"Nuevo Sindicalismo" y Represión Judicial en el Brasil de la "apertura": las huelgas metalúrgicas en São Bernardo do Campo y São José dos Campos (1980-85)}

El establecimiento de legislación y tribunales de excepción, como sabemos, configuraba uno de los pilares del régimen autoritario construido en el Brasil de la década de 1960, aún en operación en el gobierno del General João Batista Figueiredo (1979-1985), algo que por sí solo demostraba la lentitud y, el gradualismo de la "apertura", ciertamente más segura para los propios militares que para el movimiento obrero. Sin embargo, cuando el Supremo Tribunal Militar evaluó el recurso de los sindicalistas del ABC, el 16 de abril de 1982, se produjo otra evidencia de la caducidad del modelo de dominación política encabezado por las Fuerzas Armadas.

Ante la corte superior de la Justicia Militar, la estrategia de la defensa fue buscar la anulación del juicio en primera instancia, partiendo de cuestiones absolutamente técnicas. Uno de los abogados de defensa, Idibal Piveta, por ejemplo, argumentó que la sesión de la Auditoría Militar que juzgaba el caso fuera interrumpida para la cena de los jueces auditores, lo que, de acuerdo con el Código Penal, representaría motivo suficiente para la anulación de un juicio. La actuación de la defensa fue descrita en la prensa del Partido de los Trabajadores, enfatizando la argumentación de los abogados que resaltaba el carácter "claramente económico" de la huelga, atestiguando que "los sindicalistas no deberían ser juzgados por Auditorías y Tribunales Militares, sino por la Justicia del Trabajo".5

Contrariando las expectativas, el Tribunal Superior de Justicia, por nueve votos a tres, aceptó la "preliminar de incompetencia" presentada por la defensa de los trabajadores, declarándose, pues, inapto a juzgar el mérito de la cuestión, y remitiendo el proceso a la Justicia Común (lo que, en la práctica, casi equivalía a una absolución, teniendo en cuenta que en el Derecho Laboral la prescripción de los crímenes ocurre en dos años, y la denuncia databa de mayo de 1980).

Podríamos interpretar el resultado del juicio como un alejamiento consciente de los militares en relación al tema cada vez más candente de las huelgas, cuyo número crecía desde el final de la década anterior. Esta postura militar puede ser un resultado no sólo del desgaste del régimen dictatorial ante la opinión pública, sino también de las tensiones internas a la corporación y del creciente predominio de una postura favorable a la restauración de la normalidad democrática entre la fracción militar "castellista" (por oposición a la llamada "línea dura", resistente a la "apertura"). Pero es igualmente cierto que, al menos desde el punto de vista jurídico, la defensa de los sindicalistas del $A B C$ se demostró hábil al apelar a las irregularidades del proceso, puesto que una estrategia que cuestionara abiertamente el mérito de la causa, denunciando la improcedencia de la caracterización de las actitudes de los huelguistas como "incitación a la subversión" o "propaganda subversiva", podría muy bien haber suscitado mayor resistencia por parte de los ministros del STM.

5 Jornal dos Trabalhadores, no 2, abr. 1982, p. 3. Acervo Centro Sérgio Buarque de Holanda - Fundação Perseu Abramo. Reproducción en Revista Perseu, no 13, Ano 2, fevereiro de 2017, 120. 


\section{Los 33 de GM}

El carácter extremadamente contradictorio de la liberalización política en curso en Brasil de la primera mitad de la década de 1980 fue nuevamente demostrado cuando el gobierno Figueiredo sancionó otra Ley de Seguridad Nacional, formalmente más blanda, en diciembre de 1983. Dos años después, cuando algunos de los trabajadores huelguistas de la automotriz General Motors de São José dos Campos fueron criminalizados por su participación en la ocupación de la empresa, parecía probable que fueran encuadrados en la nueva ley. Pero, como veremos, el proceso transcurrió de otro modo.

En la región de São José dos Campos, un importante polo industrial con gran presencia militar, considerado área estratégica para la seguridad nacional, entre otras razones, por albergar un complejo aeroespacial y bélico, el Sindicato de los Metalúrgicos (SMSJCR) fue comandado entre 1981 y 1984 por un grupo heterogéneo de sindicalistas vinculados al partido de oposición consentida de la dictadura, el MDB (en cuyo seno actuaban organizaciones comunistas de gran envergadura, como el PCB y el PC do B, aún ilegales), y al núcleo fundador del PT en la ciudad. Impulsado por las huelgas pioneras del ABC paulista, este grupo había formado, ya en 1979, una Oposición metalúrgica para contraponerse a la gestión burocrática que hasta entonces dirigía la entidad, encabezada por José Domingues, miembro del partido oficial de la dictadura, la ARENA. En 1983, se produce una ruptura entre los sectores emedebistas y petistas en la dirección de la entidad, que disputarían el sindicato en listas separadas en las elecciones del año siguiente, con victoria de los petistas.

Sin embargo, había importantes divisiones incluso dentro del grupo vinculado al PT. Mientras que un sector, encabezado por José Luís Gonçalves, que sería el nuevo presidente de la entidad, tenía fuertes vínculos con la tendencia mayoritaria del partido y el sindicato de los metalúrgicos de São Bernardo do Campo, otro grupo, ligado a los trotskistas de la Convergencia Socialista (CS), partido hermano del Movimiento al Socialismo (MAS) argentino y que actuaba como corriente interna en el PT, quedaría con importantes cargos en la gestión electa en febrero de 1984. La Convergencia Socialista se vería responsabilizada por el "radicalismo" de las luchas trabadas por la categoría en el período siguiente, no sólo en las páginas de la prensa brasileña, sino también en los medios sindicales e incluso en el interior del PT.

Utilizando la táctica de tomar la fábrica para presionar a la patronal en las negociaciones, los operarios de General Motors conquistaron acuerdos ventajosos aún en el primer semestre de 1984, poco después de las elecciones, en la que fue la primera huelga ocurrida en la planta de la transnacional en la ciudad, después de 25 


\section{"Nuevo Sindicalismo" y Represión Judicial en el Brasil de la "apertura": las huelgas metalúrgicas en São Bernardo do Campo y São José dos Campos (1980-85)}

años de existencia. ${ }^{6}$ De acuerdo con el testimonio del metalúrgico Ediberto Bernardo dos Santos, apodado Hiena, que había trabajado en la Volkswagen de São Bernardo do Campo en 1979 e ingresó en la GM de São José en 1982, tras el movimiento paredista de abril de 1984, la propia fábrica no se encontraba en condiciones de promover represalias. La conducción pacífica de la huelga por los trabajadores había causado buena impresión en la sociedad (Silva, 2010: 39), y permitió el avance de la organización obrera dentro de una fábrica que hasta entonces ejemplificaba muy bien lo que Laís Abramo (1999) llamó "despotismo fabril".

En todo caso, el escenario se volvió bastante diferente en la huelga del año siguiente. El movimiento huelguista de abril de 1985 en la ciudad se inició en el contexto de la campaña salarial metalúrgica promovida por la Central Única de los Trabajadores (CUT), que colocaba como pauta central la reducción de la jornada de trabajo para 40 horas semanales. En la GM, punta de lanza de la movilización en São José, la huelga comenzó por el turno de la noche, y rápidamente se optó por la táctica de "huelga de rotación", una variante de la ocupación de fábrica, en la que los trabajadores entraban en la planta y cumplían sus turnos de brazos caídos, dejando la fábrica enseguida. Después de quince días de paralización, la patronal habría pasado a la ofensiva, con el despido de decenas de trabajadores - entre ellos dirigentes sindicales y "cipeiros" (miembros de la Comisión Interna de Prevención de Accidentes - CIPA), que gozaban de estabilidad - antes mismo que la legalidad de la huelga fuera evaluada por la Justicia del Trabajo.

La respuesta de los trabajadores fue la ocupación permanente de la fábrica. De acuerdo con Moacyr P. Silva (2010: 44), que entonces era asesor del Sindicato de los Metalúrgicos de São José dos Campos y Región (y que, en esa condición, también sería criminalizado), la reacción patronal y estatal sólo hizo endurecer: "la policía llegó, la gran prensa 'adentró la cancha', las autoridades públicas fueron sensibilizadas y la sociedad convencida del radicalismo insano de los trabajadores". Para eso, GM se basó en la decisión de los trabajadores de no permitir que cualquier persona entrara o saliera de la fábrica a partir del momento en que la ocupación fue votada por asamblea, algo que, vale decir, ya había ocurrido en la huelga del año anterior, pero que en 1985 fue rápidamente denunciado en la gran prensa como una situación de "cárcel privada" impuesta por los huelguistas a los "mensualistas" (gerentes, directores y funcionarios administrativos) que se encontraban en la planta en aquel 25 de abril. Al día siguiente, la Policía Militar cercó la fábrica y los "mensualistas" fueron liberados, pero no se cumplió la orden de reintegración de posesión, emitida a favor de GM. La ocupación, debilitada por la decisión judicial y

\footnotetext{
${ }^{6}$ Traté de las ocupaciones de fábrica como método de lucha de los metalúrgicos en los años 1980 en comunicación presentada en 2017 (Martins, 2017.). En cuanto a la huelga de 1985, discutida adelante, nuestras principales referencias son Horta (1993) y Guerra (2015).
} 


\title{
Richard De Oliveira Martins
}

por el alarde en torno al supuesto "secuestro", terminó el 27 de abril; la huelga duraría hasta el 9 de mayo, pero los obreros no lograrían revertir los despidos.

La represión, por otro lado, estaba apenas comenzando: el gobierno del estado de São Paulo inició una investigación y se abrió un proceso penal contra 33 personas, entre dirigentes sindicales, miembros de la comisión interna (fundada poco antes) e incluso trabajadores sin militancia política o sindical, acusados como "agitadores" o líderes de la huelga por directores y empleados del sector administrativo de General Motors. Además, cerca de 400 trabajadores fueron despedidos tras el fin de la huelga, y pasaron a formar parte de una lista negra, viéndose "prácticamente excluidos del mercado formal de trabajo del Valle del Paraíba" (Silva, 2010: 44).

Para Luiz Eduardo Greenhalgh, abogado vinculado al Partido de los Trabajadores y que actuó tanto en la defensa de los sindicalistas del ABC, en 1980, como en el caso de los "33 de GM", en 1985, la denuncia presentada contra los obreros de São José dos Campos iniciaba "un proceso eminentemente político, aunque sin ley de seguridad nacional", caracterizado por la "articulación de las medidas represivas de los poderes del Estado y del Capital".7 De acuerdo con Greenhalgh, cuando se iniciaron los despidos, los trabajadores creyeron que la empresa sería obligada por la Justicia a volver atrás:

\begin{abstract}
"Confiaron en los textos legales que dan estabilidad a los dirigentes sindicales, a los ciperos [miembros de la Comisión Interna de Prevención de Accidentes] y a los integrantes de las Comisiones Internas. Creyeron en TRT y en la legislación laboral. En ésta, porque veda la dispensa de trabajadores en huelga, antes de la apreciación de su legalidad por la Justicia del Trabajo. En él [TRT], porque cuando juzgara el dissidio colectivo, determinaría la readmisión inmediata de los ilegalmente dispensados. ... Ledo engaño. La Justicia Laboral decretó el movimiento ilegal y [la empresa] no readmitió a nadie." (Greenhalgh Apud Horta, 1993: 109-10).
\end{abstract}

La denuncia presentada contra los "33 de GM" a partir de la investigación policial reprodujo la versión que la empresa buscaba dar a los hechos, y en vez de poner de relieve el contenido político supuestamente "subversivo" de la huelga, prefirió asociarla a crímenes comunes, como los de secuestro y cárcel privada (Artigo 128). Sin embargo, dos de los ocho artículos supuestamente infringidos por los acusados, a saber, el 197 (Atentado contra la libertad de trabajo) y el 202 (Invasión de establecimiento industrial, comercial o agrícola.; Sabotaje), hacían indiscutible que el proceso trataba de "crímenes resultantes de huelga", que, de acuerdo con la

\footnotetext{
7 Según Greenhalgh, "la huelga tenía, al principio, objetivos casi exclusivamente salariales. Los trabajadores ingresaban en las dependencias de la fábrica y, adentro, quedaban de brazos caídos. El movimiento era organizado, disciplinado y pacífico. Los trabajadores demostraban gran aliento. La empresa aguantó, por quince días, el 'juego democrático'. Después, rompió con él violentamente. ... Aterrorizó. Mostró todas las posibilidades represivas que tenía. Las articuló y las arrojó vigorosamente sobre el Sindicato de los Metalúrgicos de São José dos Campos, sobre sus dirigentes, sobre los líderes de la huelga" (Greenhalgh Apud Horta, 1993).
} 


\section{"Nuevo Sindicalismo" y Represión Judicial en el Brasil de la "apertura": las huelgas metalúrgicas en São Bernardo do Campo y São José dos Campos (1980-85)}

Constitución de 1967, entonces aún en vigor, debían ser juzgados en la esfera federal, lo que fue reivindicado por la defensa, de modo a postergar el proceso.

Remitido a la Justicia Federal por decisión de la Sexta Câmara Criminal do Tribunal de Justiça de São Paulo, en noviembre de 1986, el caso sería nuevamente alterado por la promulgación de la Constitución de 1988, que pasaba a encaminar a la Justicia Federal sólo los crímenes contra la organización del trabajo relacionados a órganos o instituciones públicas. Además, de acuerdo con el art. $8^{\circ}$ del Acta de las Disposiciones Constitucionales Transitorias (ADCT), debería concederse amnistía a los trabajadores de empresas privadas cesanteados por participación en huelgas, si se caracterizaba la motivación política de los despidos. La defensa de los "33 de la GM", presentada ante la Justicia Federal ya en junio de 1992, reclamaba tales dispositivos, argumentando que no competía a aquella instancia juzgar el caso. Pero no se limitaba a eso, cuestionando, igualmente, el mérito del proceso, puesto que, según los abogados, los autos no comprobaban la autoría y ni siquiera la ocurrencia de los crímenes denunciados.

No tuvimos acceso a la sentencia dictada por la Justicia Federal, pero sabemos que los "33 de GM" jamás tuvieron que cumplir pena por las acusaciones, lo que indica su absolución o la prescripción de las denuncias. Más tarde, en los años 2000, por lo menos veintinueve de ellos ya habían sido, finalmente, amnistiados, prueba del reconocimiento formal por parte del Estado brasileño del carácter político de la persecución que sufrieron.

\section{Consideraciones finales}

De acuerdo con Maria Celina D'Araújo (2006), la Ley de Seguridad Nacional de 1983, aún en vigor, "en tiempos de democracia y de Estado de Derecho" se habría vuelto anacrónica, puesto que "los crímenes allí previstos pueden ser juzgados por la aplicación de otras leyes penales y criminales". La criminalización del movimiento huelguista de 1985 en General Motors de São José dos Campos, con base en el Código Penal, en nuestra opinión, confirma esta interpretación, evidenciando que el recurso a los tribunales de excepción en la represión de las huelgas, aunque todavía posible, ya no configuraba una táctica interesante para los actores estatales. La estrategia de criminalización pasaba a ser el intento de asociar, con el apoyo de la patronal y de la prensa, las movilizaciones obreras a crímenes comunes en vez de crímenes políticos. A pesar de su cada vez más evidente desgaste, la Ley de Seguridad Nacional sería movilizada en algunas ocasiones contra opositores durante la "apertura", y en abril de 1986, la "Nueva República" vería su primer condenado político, Vicente Paulo da Silva, líder sindical petista acusado de haber calumniado al presidente Figueiredo tres años antes. Sin embargo, un caso muy particular, ocurrido en el mismo mes, refuerza la hipótesis de la progresiva caducidad de la LSN para la represión política, 


\section{Richard De Oliveira Martins}

incluso ante un episodio cuyo carácter criminal, ante la legislación vigente, era inequívoco.

Se trata del asalto a una sucursal del Banco do Brasil en Salvador, promovido por militantes del Partido Comunista Brasileiro Revolucionário, tendencia que actuaba en el interior del PT, cuya supuesta finalidad sería levantar recursos para contribuir con la Nicaragua sandinista. Arrestados en flagrante, los militantes (sumariamente expulsados por la dirección del PT, que repudió el asalto) serían investigados tanto por la Policía Federal como por la Policía Civil de Bahía, y acabarían enjuiciados, por el mismo crimen, simultáneamente en la Justiça Estadual (por delito contra el patrimonio) y en la Justiça Militar (por delito contra la seguridad nacional), estableciendo un claro conflicto de competencias, que se prolongaría durante algunos meses, hasta que en agosto del mismo año la Auditoría militar renunció al caso, dejando que el Ministerio Público de Bahía se encargara de él. Según Lucas Torres (2017:123), es posible atribuir la actitud de los militares a "la posibilidad futura de amnistía para los presos políticos condenados por una Ley de Seguridad Nacional incompatible con la democracia que se constituía" - en aquel entonces, faltaban pocos meses para la elección del Congresso Constituinte. Es razonable suponer, como hace Torres (2017:124) que, en medio de las incertidumbres de la transición, la Auditoría haya percibido que una condena emitida por un tribunal militar podría ser más frágil que una sentencia de la Justicia común.

Consideraciones del mismo tipo, seguramente, se han hecho presentes en la elaboración de la estrategia de judicialización del conflicto en General Motors de la que tratamos aquí. Al recurrir a la justicia común para hacer frente a la movilización, los gobiernos alcanzaban el objetivo de retirar las cuestiones laborales de la esfera de la Justiça do Trabalho (en la que las posibilidades represivas y el efecto de disuasión sobre el conjunto de los trabajadores eran menores), mientras que mantenían a los militares alejados de la interferencia directa sobre estas cuestiones. Hay que tener en cuenta que, incluso para asegurar la "tutela militar"8 sobre la llamada "redemocratización", no era conveniente que las Fuerzas Armadas (y, especialmente, sus cúpulas, entre ellas el STM) se vieran demasiado asociadas a la represión de movimientos huelguistas, teniendo en cuenta que los costos de esa participación tendían a ser mucho mayores que las ganancias.

Esto, sin embargo, no impediría que el brazo armado del Estado, sobre todo a través de las Policías Militares (bajo las órdenes de los gobiernos de los estados), siguiera interviniendo sobre las movilizaciones obreras. Incluso el Ejército sería convocado para desbaratar movimientos huelguistas en los años siguientes, como en el trágico episodio de la invasión de la Companhia Siderúrgica Nacional (CSN) de Volta Redonda (RJ) en 1988, ocasión en que los militares asesinaron a tres obreros.

Por otro lado, percibimos que, ante los tribunales del período de la "apertura política", en ambos casos aquí analizados, los defensores de los activistas y

${ }^{8}$ La expresión es utilizada por diversos autores para caracterizar el control militar sobre el ritmo y los límites impuestos al proceso de liberalización política en Brasil. Véase, por ejemplo, Oliveira (1994). 


\section{"Nuevo Sindicalismo" y Represión Judicial en el Brasil de la "apertura": las huelgas metalúrgicas en São Bernardo do Campo y São José dos Campos (1980-85)}

sindicalistas procesados reforzaron los motivos económicos de las huelgas criminalizadas, en detrimento de sus aspectos políticos (sobre todo, el cuestionamiento a los gobiernos de Figueiredo y Sarney), sobre los cuales el "nuevo sindicalismo", en otros ámbitos, demostraba tener una comprensión firme. Evidentemente, esta estrategia de defensa reconocía que los juicios en la esfera criminal ocurrían en una arena mucho más peligrosa que la de la justicia laboral, implicando gran riesgo para los acusados y para el conjunto del movimiento, ya que las posibles condenas podrían tener un grave efecto desmovilizador sobre amplios sectores de la clase trabajadora que iniciaban un proceso de reorganización y experimentación, y que tenían en esos sindicalistas una referencia. Justamente por eso, parte importante de la defensa de los dirigentes criminalizados implicaba demostrar la naturaleza política de la persecución que sufrían, incluso al conducir luchas esencialmente "económicas".

Concluyendo este artículo, debemos destacar que estos procesos criminales, que constituyeron dos de los intentos más ostensibles de criminalización contra el movimiento obrero brasileño en los años 1980, parecen haber sido excepcionales, ya que la gran mayoría de las huelgas del período dio lugar a negociaciones y juicios en el ámbito de la Justicia Laboral. Aún así, sirvieron al propósito de la represalia y la intimidación, pero no pudieron desestructurar las direcciones sindicales criminalizadas, y ciertamente no fueron lo bastante para contener el ciclo de huelgas en curso, que siguió intensificándose, en una coyuntura de alta inestabilidad económica y política. Sin embargo, junto con otras formas de represalia estatal y patronal, la criminalización de huelgas (y de las luchas sociales, en general) y la persecución de activistas ha logrado, paulatinamente, imponer límites más restrictos a las movilizaciones obreras y populares.

Evidentemente, en este escenario la represión es un factor entre varios; hay que tener en cuenta otras transformaciones y readecuaciones estratégicas, tanto por parte de la patronal - involucrando procesos de reestructuración productiva y modificaciones en las técnicas gerenciales (Tumolo, 2002) - cuanto entre los distintos sectores del movimiento obrero - por una parte, con el fortalecimiento del sindicalismo de resultados o de colaboración (Graciolli, 2007), y otro, con el desarrollo de tendencias burocráticas en el marco del "nuevo sindicalismo" y en la Central Única dos Trabalhadores (Santana, 1995), pari passu con la consolidación de la estrategia de ocupar espacios en el aparato de Estado a través de la vía electoral, adoptada por el Partido de los Trabajadores (Iasi, 2006; Secco, 2011). Estos fenómenos, ricos en ambigüedades, matices y contradicciones, culminaron en el reflujo de las luchas obreras a partir de la década de 1990, bajo el impacto del proyecto neoliberal implementado por los sucesivos gobiernos de la "Nueva República". 


\section{Richard De Oliveira Martins}

\section{Bibliografía}

Abramo, L. W. (1999). O resgate da dignidade: greve metalúrgica e subjetividade operária. Campinas/São Paulo: Editora da Unicamp/Imprensa Oficial.

Antunes, R. (1992). A Rebeldia do Trabalho: O confronto operário no ABC paulista: as greves de 1978/80, 2ª ed. Campinas/SP: Ed. da Unicamp.

Corrêa, L. (2013). A "rebelião dos índices": Política salarial e Justiça do Trabalho na Ditadura Civil-Militar (1964-1968). En A. C. Gomes \& F. T. Silva (Comp.). A Justiça do Trabalho e sua história: os direitos dos trabalhadores no Brasil. Campinas/SP: Editora da Unicamp.

Corrêa, L. \& Fontes, P. (2016). As falas de Jerônimo: Trabalhadores, sindicatos e a historiografia da ditadura militar. Anos 90, Porto Alegre, v. 23, n. 43: 129-51.

D’Araújo, M. C. (2006.) Justiça Militar, segurança nacional e tribunais de exceção. Conferencia presentada al $30^{\circ}$ Encontro Anual da ANPOCS, Caxambu/MG, Brasil.

Graciolli, E. (2007.) Privatização da CSN: da luta de classes à parceria. São Paulo: Expressão Popular.

Guerra, C. (2015.) "Mais vale um ano de leão que cem anos de cordeiro": Trajetórias dos metalúrgicos de São José dos Campos (Tesis de maestria inédita). Instituto de Filosofia e Ciências Humanas/Unicamp, Campinas.

Horta, C. (1993.) A Greve da GM. São Paulo: Página Aberta.

Iasi, M. L. (2006.) As metamorfoses da consciência de classe: o PT entre a negação e o consentimento. São Paulo: Expressão Popular.

Keck, M. E. 0 "novo sindicalismo" na transição brasileira. En A. Stepan. (Comp.). Democratizando o Brasil. Trad. Ana Luíza Pinheiro et al. Rio de Janeiro: Paz e Terra.

Macedo, F. B. (2015.) Social networks and urban space: worker mobilization in the first years of "New Unionism" in Brazil. International Review of Social History, n. $\stackrel{0}{60}$ : 37-71.

Mattos, M. B. (1998.) Novos e velhos sindicalismos no Rio de Janeiro (1955-1988). Rio de Janeiro: Vicío de Leitura. 


\section{"Nuevo Sindicalismo" y Represión Judicial en el Brasil de la "apertura": las huelgas metalúrgicas en São Bernardo do Campo y São José dos Campos (1980-85)}

Martins, R. (2017.) A tática das ocupações de fábrica na década de 1980: greves do setor metalúrgico em São José dos Campos (SP) e Volta Redonda (RJ). Ponencia presentada al XIX Simpósio Nacional de História. Brasília/DF, Brasil.

Morel, R. \& Mangabeira, W. (1994.) "Velho" e "novo" sindicalismo e uso da Justiça do Trabalho: um estudo comparativo com trabalhadores da Companhia Siderúrgica Nacional. Dados, v. 37, no 1 .

Negro, A. L. (1999.) Nas origens do "Novo Sindicalismo": o maio de 59, 68 e 78 na indústria automobilística. En I. Rodrigues. (Comp.) O Novo Sindicalismo. Vinte anos depois. Petrópolis/RJ: Vozes/Educ/Unitrabalho.

Negro, A. L. (2004.) Linhas de Montagem. $O$ industrialismo nacionaldesenvolvimentista e a sindicalização dos trabalhadores. São Paulo: Boitempo/Fapesp.

Oliveira, E. (1994.) De Geisel a Collor: Forças Armadas, transição e democracia. Campinas: Papirus.

Rezende, V. (2013) Da gratidão à luta por direitos: a regulamentação das relações de trabalho na "capital do calçado" (Franca-SP, 1940-1980). En A. C. Gomes \& F. T. Silva (Comp.). A Justiça do Trabalho e sua história: os direitos dos trabalhadores no Brasil. Campinas/SP: Editora da Unicamp.

Rezende, V. (2017.) Vidas Fabris: Trabalho e conflito social no complexo coureirocalçadista de Franca-SP (1950-1980). São Paulo: Alameda.

Sader, E. (1995.) Quando novos personagens entraram em cena: experiências e lutas dos trabalhadores da Grande São Paulo 1970-1980, 2ª ed. Rio de Janeiro: Paz e Terra.

Santana, M. A. (1995.) Cultura sindical e identidade nos anos 80/90. Revista de Ciências Humanas, Florianópolis, v. 13 n.17-18: 82-90.

Secco, L. (2011.) História do PT 1978-2010. Cotia: Atêlie Editorial.

Silva, F. T. (2013) Entre o Acordo e o Acórdão: a Justiça do Trabalho paulista na antevéspera do golpe de 1964. En A. C. Gomes \& F. T. Silva (Comp.). A Justiça do Trabalho e sua história: os direitos dos trabalhadores no Brasil. Campinas/SP: Editora da Unicamp. 


\section{Richard De Oliveira Martins}

Silva, M. P. (2010.) Hiena - minha revolta não se vende. São José dos Campos/SP: Mogiana.

Torres, L. M. P. (2017.) Estratégias de uma esquerda armada: militância, assaltos e finanças do PCBR na década de 1980. Salvador: EDUFBA.

Tumolo, P. S. (2002.) Da contestação à conformação: A formação sindical da CUT e a reestruturação capitalista. Campinas/SP: Editora da Unicamp.

Recibido: 30/09/2019

Evaluado: 20/10/2019

Versión Final: 24/11/2019 